\title{
A Novel Chromosomal Aberration in the Pathogenesis of Transient Leukemia of Down Syndrome
}

\author{
Aakash Chandran Chidambaram ${ }^{1} \cdot$ Jaikumar Govindaswamy Ramamoorthy ${ }^{1} \cdot$ Nishad Plakkal $^{2} \cdot$ Guruprasad Peruri $^{2}$. \\ Chinnasamy Kannan ${ }^{2} \cdot$ Sarasu Jayaraman ${ }^{3} \cdot$ Nivedita Mondal $^{2}$
}

Received: 14 November 2020 / Accepted: 8 February 2021 / Published online: 15 March 2021

(C) Dr. K C Chaudhuri Foundation 2021

To the Editor: The index case was a term girl with a smooth perinatal transition with Down phenotypic features. Examination revealed hepatosplenomegaly (liver span-7 cm and spleen $2 \mathrm{~cm}$ below the left costal margin). Blood investigations done on day 3 of life revealed hemoglobin of $12.8 \mathrm{~g} / \mathrm{dL}$, total leukocyte count 32,450 cells $/ \mu \mathrm{L}$ and platelets $1,83,000$ cells $/ \mu \mathrm{L}$. The peripheral smear showed a left-shift with $34 \%$ myeloid blasts which were positive for CD41, CD61 on flow cytometry. Since there was leucocytosis with nonerythroid blasts $\geq 10 \%$ consistently in a background of Down phenotype, GATA1 mutation was not looked for and a diagnosis of transient leukemia of Down syndrome (TL-DS) was made based on Children Oncology Group (COG) and World Health Organisation (WHO) guidelines $[1,2]$. The karyotyping was later confirmed to be $47, \mathrm{XX}, \mathrm{t}(1 ; 13)(\mathrm{q} 31 ; \mathrm{q} 21),+21 \mathrm{c}[25]$. The infant developed rapidly progressing liver dysfunction and succumbed over the next $3 \mathrm{~d}$.

The molecular pathogenesis of TL-DS is complex and is believed to be driven by mutations in the GATAl gene. Karyotyping of our index case revealed a novel abnormality, balanced translocation $(1 ; 13)(\mathrm{q} 31 ; \mathrm{q} 21)$. This translocation has not been described in the literature so far in infants with TL-DS. The locus $13 \mathrm{q} 21$ is suspected to be a candidate region for familial chronic lymphocytic leukemia. Five genes from 13q21.33-q22.2, have putative function related to cell growth

Nivedita Mondal

nive.m8@gmail.com

1 Department of Pediatrics, Jawaharlal Institute of Postgraduate Medical Education and Research (JIPMER), Puducherry, India

2 Department of Neonatology, Jawaharlal Institute of Postgraduate Medical Education and Research (JIPMER), Puducherry 605006, India

3 Department of Anatomy \& Cytogenetics, Jawaharlal Institute of Postgraduate Medical Education and Research (JIPMER), Puducherry, India
[3]. Some of these genes are deregulated in breast and prostate cancer. Additionally, chromosome 1q contains the ELK4 gene, a member of the E26 transformation specific (ETS) transcription factor family. It has been postulated that alterations and the consequent imbalance of chromosome 1 may be causative for certain types of cancer. AML-M2 has been previously associated with $\mathrm{t}(1 ; 13)$ translocations with different breakpoints, but (q31;q21) has not been implicated in the causation of TL-DS till now [4]. The unusual rapid deterioration/disease progression in a case of TL-DS depends on the third hit. The role of this translocation as a third hit in the pathogenesis of TL-DS/ML-DS needs to be studied.

\section{Declarations}

Conflict of Interest None.

\section{References}

1. Gamis AS, Alonzo TA, Gerbing RB, et al. Natural history of transient myeloproliferative disorder clinically diagnosed in Down syndrome neonates: a report from the Children's Oncology Group Study A2971. Blood. 2011;118(26):6752-9.

2. Arder DA, Baumann I, Niemeyer CM, Brunning RD, Porwit A. Myeloid proliferations associated with down syndrome. In: Swerdlow SH, Campo E, Harris NL, et al., editors. WHO Classification of Tumours of Haematopoietic and Lymphoid Tissues. Lyon: IARC; 2017. p. 169-71.

3. $\mathrm{Ng} \mathrm{D}$, Toure $\mathrm{O}$, Wei MH, et al. Identification of a novel chromosome region, 13q21.33-q22.2, for susceptibility genes in familial chronic lymphocytic leukemia. Blood. 2007;109(3):916-25.

4. Unbalanced whole-arm translocation $\operatorname{der}(1 ; 13)$ in hematologic malignancies [Internet]. Atlasgeneticsoncology.org. 2020. Available at: http://atlasgeneticsoncology.org/Anomalies/der0113q10q10ID1653. html. Accessed 27 June 2020.

Publisher's Note Springer Nature remains neutral with regard to jurisdictional claims in published maps and institutional affiliations. 